\title{
Differences in estrogen and progesterone receptor expression in endometrial polyps and atrophic endometrium of postmenopausal women with and without exposure to tamoxifen
}

\author{
ROGERIO BARROS FERREIRA LEÃO ${ }^{1}$, LILIANA ANDRADE ${ }^{2}$, JOSE VASSALO $^{2}$, \\ ARMANDO ANTUNES JR ${ }^{1}$, AARÃO PINTO-NETO ${ }^{1}$ and LUCIA COSTA-PAIVA ${ }^{1}$ \\ Departments of ${ }^{1}$ Obstetrics and Gynecology and ${ }^{2}$ Pathological Anatomy, School of Medicine, \\ State University of Campinas (UNICAMP), Campinas, 13083-881 São Paulo, Brazil
}

Received May 10,2013; Accepted August 13, 2013

DOI: $10.3892 / \mathrm{mco} .2013 .180$

\begin{abstract}
Postmenopausal women who use tamoxifen present with an increased incidence of endometrial alterations, such as polyps and hyperplasia, in addition to a higher risk of malignant endometrial neoplasms. Among these endometrial changes, polyps are the most common, with a pathogenesis associated with hormonal influence. The objective of this study was to compare the expression of estrogen receptors (ERs) and progesterone receptors (PRs) in endometrial polyps from tamoxifen users with that in endometrial polyps and the atrophic endometrium of postmenopausal tamoxifen non-users. Among women undergoing surgical hysteroscopy, 84 tamoxifen users with benign endometrial polyps were selected. This group was compared to 84 samples of atrophic endometrium and to 252 benign polyps from postmenopausal women who were not treated with tamoxifen. The expression of ER/PR was assessed by immunohistochemical analysis, according to the percentage of stained cells, intensity of nuclear staining and final score. The polyps from tamoxifen users exhibited a higher expression of ER and PR in the glandular epithelium and stroma compared to the atrophic endometrium $(\mathrm{P}<0.0001)$. Compared to the polyps from women not treated with tamoxifen, tamoxifen users exhibited a higher PR expression in the epithelium $(\mathrm{P}=0.0014)$ and stroma $(\mathrm{P}=0.0056)$, with no difference in the expression of ER. In conclusion, endometrial polyps frequently exhibit an increase in ER expression, regardless of tamoxifen use. High levels of PR expression appear to be consistent with the estrogen agonist effects of tamoxifen.
\end{abstract}

Correspondence to: Dr Lucia Costa-Paiva, Department of Obstetrics and Gynecology, State University of Campinas (UNICAMP), 101 Rua Alexander Fleming, Campinas, 13083-881 São Paulo, Brazil E-mail: paivaepaiva@uol.com.br

Key words: endometrial polyp, tamoxifen, estrogen receptor, progesterone receptor

\section{Introduction}

Tamoxifen is an antineoplastic drug used in the treatment of estrogen receptor (ER)-positive breast cancer (1). The mechanism of action of tamoxifen in breast cancer is the inhibition of cancer cell growth by the competitive antagonism of estrogen at the ER (2). In the classic model of estrogen stimulation, estrogen binds to the ER, which is inactive in the nucleus, inducing conformational changes in the receptor, facilitating its binding to specific DNA sites (referred to as estrogen response elements) and to coactivator proteins (amplified in breast 1, CREB-binding protein/p300 and steroid receptor coactivator-3), which activate the genes that encode progesterone receptors (PRs), as well as those that encode mitogenic growth factors, such as transforming growth factor- $\alpha$, vascular endothelial growth factor, platelet-derived growth factor, insulin-like growth factor 1 and insulin receptor substrate (2-5). In breast cells, the tamoxifen-receptor complex recruits nuclear receptor corepressor and silencing mediator of retinoic acid and thyroid hormone receptor, thereby repressing the transcription of these genes (6).

However, despite its antagonist effect on breast tissue, tamoxifen behaves as a partial estrogen agonist in the endometrium (7). During the premenopausal period, when estrogen concentrations are high, tamoxifen exerts an antagonist effect, whereas during the postmenopausal period, when estrogen concentrations are low, it exerts an agonist effect (8).

A higher incidence of endometrial alterations, such as polyps, hyperplasia, carcinoma and sarcoma, have been reported in menopausal tamoxifen users, in addition to an increased risk of endometrial malignant neoplasms (9-14).

Among the endometrial alterations reported in tamoxifen users, polyps are the most common, with a prevalence of $13-30 \%(10,12,15,16)$. In patients treated with tamoxifen, microscopic analysis revealed that polyps are more translucent, edematous and fibrotic, with less stromal cellularity (10).

The stimulating factor for focal endometrial growth has not been determined. However, it has been hypothesized that a significant hormonal influence exists. Previous studies demonstrated a higher ER expression in the epithelium and stroma of the endometrial polyps from menopausal patients 
in comparison to the adjacent atrophic endometrium (17-19). With regard to the expression of PR, previous studies have demonstrated a higher expression in the epithelium and not the stroma of the polyp, compared to the adjacent atrophic endometrium (17-20). This finding suggests that endometrial polyps have a higher sensitivity to estrogen and progesterone and may develop even in the presence of low serum hormone concentrations (19).

Previous studies comparing polyps from tamoxifen users to those from non-users have reported lower ER expression and increased PR expression in tamoxifen users, demonstrating an agonist effect of tamoxifen on the endometrium. However, only few small case studies are available, reporting variable results (21-24).

Therefore, the pathophysiology and malignant potential of endometrial polyps have not been fully elucidated, nor has the mechanism underlying the tamoxifen-induced endometrial alterations. Increased knowledge of the hormonal factors involved in this process may contribute to a better understanding of this disorder and the optimal approach may be applied in the treatment of endometrial diseases in breast cancer patients using adjuvant therapy with tamoxifen.

The aim of this study was to assess the expression of $\mathrm{ER} / \mathrm{PR}$ in the endometrial polyps from menopausal tamoxifen users, compared to that in the atrophic endometrium and in polyps from menopausal women who were not treated with tamoxifen.

\section{Materials and methods}

Data collection. This study was conducted in the Professor Dr José Aristodemo Pinotti Women's Hospital (CAISM/UNICAMP) and was approved by the Research Ethics Committee of the State University of Campinas (protocol no. 004/2010). According to the information retrieved from the computerized database of this institution, a total of 1,050 women underwent surgical hysteroscopy for endometrial polypectomy between January, 1998 and December, 2008. All the premalignant or malignant polyps were excluded from this study. From the entire sample, the postmenopausal tamoxifen users histologically diagnosed with benign endometrial polyp and normal adjacent endometrium, as evaluated by hysteroscopy, were selected $(n=84)$. This group was compared to two other groups of women: a second group of 84 samples of atrophic endometrium obtained from postmenopausal women who did not receive hormone therapy (HT) and a third group of benign polyps from postmenopausal non-users of tamoxifen with no previous history of HT use. For this latter group, three controls (tamoxifen non-users with polyps) were selected for each polyp from tamoxifen users, totaling 252 females. The subjects were selected by simple random sampling. The sample units were uniformly distributed (all subjects had the same probability of being selected) using SAS software, version 9.2 (SAS Institute Inc., Cary, NC, USA).

Clinical, histopathological and hysteroscopic findings were collected from patient records. The clinical characteristics assessed were age, postmenopausal bleeding, arterial hypertension, obesity and diabetes mellitus.

A surgical hysteroscopy was performed by a gynecologist, with the patient under spinal anesthesia. A 10-mm monopolar gynecologic resectoscope with a loop electrode was used for the procedure (Karl Storz GmbH \& Co. KG, Tuttlingen, Germany). A $1.5 \%$ glycine solution was used for the distension of the uterine cavity. The endocervical canal and uterine cavity were assessed and hysteroscopic resection was performed using monopolar energy.

The endometrial samples were analyzed by pathologists of the Department of Pathological Anatomy of the UNICAMP School of Medicine, using hematoxylin and eosin (H\&E) staining.

Construction of tissue microarray (TMA). Initially, a pathologist from the Department of Pathological Anatomy at the UNICAMP School of Medicine examined the sections representative of H\&E stained endometrial polyps. Two regions that best represented the stroma and glandular epithelium were selected for the construction of TMA and a technique validated for the endometrium was adopted (25). The selected regions were then identified in the archival paraffin blocks (donor block). Subsequently, the marked donor blocks were sent to the Laboratory of Immunohistochemistry in the Department of Pathological Anatomy of the A.C. Camargo Cancer Hospital (São Paulo, Brazil) for the construction of recipient blocks with the TMA technique. A tissue microarrayer (Beecher Instruments, Silver Spring, MD, USA) available at the Department of Pathological Anatomy of the AC Camargo Cancer Hospital was used. Cylinder cones $(1.0 \mathrm{~mm})$ from the region of interest were obtained and transferred to a new block with a two-dimensional layout and intercore spacing of $0.2 \mathrm{~mm}$, as determined and recorded by the equipment. From this new block, referred to as the 'recipient block', histological sections were obtained with a manual microtome and transferred using adhesive tape to special adhesive-coated slides (Instrumentics Inc., Hackensack, NJ, USA). The adhesive tape was removed under exposure to ultraviolet light and the slides were stored, paraffin-embedded, vacuum-packed and frozen at $-20^{\circ} \mathrm{C}$.

Immunohistochemistry. ER and PR expression was assessed in the Laboratory of Immunohistochemistry of the Department of Pathology at the A.C. Camargo Cancer Hospital. The 5- $\mu \mathrm{m}$ TMA sections were deparaffinized for $24 \mathrm{~h}$ at $60^{\circ} \mathrm{C}$ in an incubator. Subsequently, the slides were rinsed in xylene at $60^{\circ} \mathrm{C}$ for $20 \mathrm{~min}$, followed by xylene at room temperature for $20 \mathrm{~min}, 100 \%$ ethanol for $30 \mathrm{sec}, 85 \%$ ethanol for $30 \mathrm{sec}$ and $70 \%$ ethanol for $30 \mathrm{sec}$. The slides were then washed in distilled tap water.

A citrate buffer solution $(10 \mathrm{mM}, \mathrm{pH}$ 6.0) was heated to boiling point in an Eterna pressure cooker (Nigro, Araraquara, Brazil) without sealing the lid, immersing the slides into boiling retrieval buffer. The cooker was sealed with the safety valve in the open position. Following release of the saturated vapor, the safety valve was lowered until total pressurization. Timing of the duration of antigen retrieval was initiated ( $\sim 4 \mathrm{~min})$. The cooker remained closed under tap water until complete depressurization was achieved. The lid of the cooker containing the slides was removed and the slides were washed in distilled tap water.

An endogenous peroxidase block was performed with $3 \%$ hydrogen peroxide $\left(\mathrm{H}_{2} \mathrm{O}_{2}-10 \mathrm{vol}\right)$ with 3 changes of $10 \mathrm{~min}$ each. The slides were washed with distilled tap water and phosphate buffered saline (PBS; $10 \mathrm{mM}, \mathrm{pH} 7.4$ ) for $5 \mathrm{~min}$. 
Table I. Clinical characteristics of postmenopausal tamoxifen users with benign polyps, tamoxifen non-users with benign polyps and tamoxifen non-users with atrophic endometrium $(n=420)$.

\begin{tabular}{|c|c|c|c|c|c|c|c|c|}
\hline \multirow[b]{2}{*}{ Characteristics } & \multicolumn{2}{|c|}{$\begin{array}{c}\text { Atrophic } \\
\text { endometrium } \\
\quad(n=84)\end{array}$} & \multirow[b]{2}{*}{ P-value ${ }^{a}$} & \multicolumn{2}{|c|}{$\begin{array}{c}\text { Polyps from } \\
\text { tamoxifen users } \\
(n=84)\end{array}$} & \multirow[b]{2}{*}{ P-value ${ }^{b}$} & \multicolumn{2}{|c|}{$\begin{array}{l}\text { Polyps from } \\
\text { tamoxifen non-users } \\
\qquad(\mathrm{n}=252)\end{array}$} \\
\hline & No. & Percentage & & No. & Percentage & & No. & Percentage \\
\hline $\begin{array}{l}\text { Postmenopausal } \\
\text { bleeding }\end{array}$ & & & 1.0000 & & & $<0.0001^{\mathrm{c}}$ & & \\
\hline Yes & 7 & 9.6 & & 7 & 8.5 & & 103 & 41.9 \\
\hline No & 66 & 90.4 & & 75 & 91.5 & & 143 & 48.1 \\
\hline $\begin{array}{l}\text { Arterial } \\
\text { hypertension }\end{array}$ & & & 0.3717 & & & 0.4362 & & \\
\hline Yes & 35 & 47.9 & & 50 & 60.2 & & 173 & 68.9 \\
\hline No & 38 & 52.1 & & 33 & 39.8 & & 78 & 31.1 \\
\hline DM & & & 0.6336 & & & 0.0531 & & \\
\hline Yes & 8 & 11.0 & & 15 & 18.1 & & 79 & 31.6 \\
\hline No & 65 & 89.0 & & 68 & 81.9 & & 171 & 68.4 \\
\hline BMI & & & 1.0000 & & & $<0.0001^{\mathrm{c}}$ & & \\
\hline$<30$ & 48 & 66.7 & & 57 & 67.9 & & 105 & 42.3 \\
\hline$\geq 30$ & 24 & 33.3 & & 27 & 32.1 & & 143 & 57.7 \\
\hline
\end{tabular}

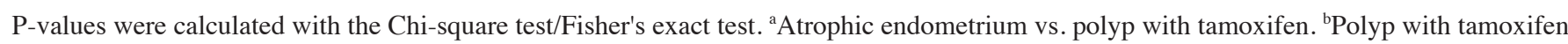
vs. polyp without tamoxifen. ${ }^{\mathrm{C}} \mathrm{P}$-value corrected by the Bonferroni method (independent tests). DM, diabetes mellitus; BMI, body mass index.

The slides were incubated with the primary antibody diluted in predetermined titer in PBS buffer containing $1 \%$ bovine serum albumin (A9647; Sigma-Aldrich, St. Louis, MO, USA) and $0.1 \%$ sodium azide $\left(\mathrm{NaN}_{3}\right)$ for $18 \mathrm{~h}$ in a humidity chamber at $4^{\circ} \mathrm{C}$. Primary monoclonal antibodies against ER (code M7047, clone 1D5, dilution 1:250; Dako, Carpinteria, CA, USA) and PR (code M3569, clone PgR 636, dilution 1:500; Dako) were used in the procedure.

The slides were washed in PBS buffer with 3 changes of 3 min each, incubated for $30 \mathrm{~min}$ at $37^{\circ} \mathrm{C}$ with Advance ${ }^{\mathrm{TM}} \mathrm{HRP}$ Link (code no. K4068; Dako) and washed with PBS buffer, with 3 changes of 3 min each. The slides were subsequently incubated with Advance HRP Enzyme for $30 \mathrm{~min}$ at $37^{\circ} \mathrm{C}$ and washed with PBS buffer, with 3 changes of 3 min each. The slides were incubated in substrate solution consisting of $100 \mathrm{mg} \mathrm{3,3'} \mathrm{diami-}$ nobenzidine tetrahydrochloride (code D-5637, Sigma-Aldrich), $1 \mathrm{ml}$ of dimethyl sulphoxide, $1 \mathrm{ml}$ of $6 \% \mathrm{H}_{2} \mathrm{O}_{2}$ (20 vol) and $100 \mathrm{ml} \mathrm{PBS}$ for $5 \mathrm{~min}$ at $37^{\circ} \mathrm{C}$ and protected from light. The slides were washed in distilled tap water for $3 \mathrm{~min}$ and counterstained with Harris' hematoxylin for $1 \mathrm{~min}$. The slides were then thoroughly washed in distilled tap water and immersed twice in ammonium water $(0.5 \%$ ammonium hydroxide solution), followed by washing in distilled tap water. The slides were dehydrated in $80 \%$ ethanol for $30 \mathrm{sec}, 95 \%$ ethanol for $30 \mathrm{sec}$, twice in $100 \%$ ethanol for $30 \mathrm{sec} /$ time and 4 times in xylene for $30 \mathrm{sec} / \mathrm{time}$. The slides were then mounted in Entellan ${ }^{\circledR}$ Neu (code 1.07961; Merck, Darmstadt, Germany). Upon examination under a light microscope, a golden brown precipitate was observed as a final reaction product that varied according to the type of receptor.
Immunohistochemistry reading. The TMA slides were manually examined by a single pathologist under a conventional light microscope. The expression of ER and PR was assessed in the stroma and glandular epithelium of the polyps and evaluated using a semiquantitative method of nuclear reaction through the analysis of the percentage of stained cells, intensity of nuclear staining and final score (26). The percentage of stained cells was visually estimated and categorized in the following manner: grade 0 , none stained; grade 1 , $<1 \%$ of cells stained; grade $2,1-10 \%$ of cells stained; grade 3 , $11-33 \%$ of cells stained; grade $4,34-66 \%$ of cells stained; and grade $5,>66 \%$ of cells stained. With regard to the intensity of nuclear staining, grading was as follows: grade 0, negative; grade 1, weak reaction; grade 2, moderate reaction; and grade 3 , intense reaction (26). The sum of positivity and intensity resulted in a final score, ranging from 0-8 (excluding the value of 1). Appropriate positive and negative controls were used. According to Harvey et al (26) this scoring method is easy to learn and highly reproducible, with a $\kappa$ index of 0.87 .

Statistical analysis. The clinical characteristics between the 3 groups (benign polyps and tamoxifen users; atrophic endometrium; and benign polyps from tamoxifen non-users) were compared using the Chi-square test and Fisher's exact test, corrected by the Bonferroni method, and the Kruskal-Wallis test $(27,28)$.

The mean final scores of ER and PR expression in the glandular epithelium and stroma of the polyps from tamoxifen users was separately compared to the mean scores of ER and $\mathrm{PR}$ in the glandular epithelium and stroma of the atrophic 
Table II. Final estrogen receptor (ER) and progesterone receptor (PR) score in the glandular epithelium and stroma of benign polyps from tamoxifen users, benign polyps from tamoxifen non-users and atrophic endometrium $(n=420)$.

\begin{tabular}{|c|c|c|c|c|c|c|c|c|c|c|c|}
\hline \multirow[b]{2}{*}{ Final score } & \multicolumn{3}{|c|}{$\begin{array}{l}\text { Atrophic } \\
\text { endometrium }\end{array}$} & \multirow[b]{2}{*}{$\mathrm{P}$-value } & \multicolumn{3}{|c|}{$\begin{array}{l}\text { Polyps from } \\
\text { tamoxifen users }\end{array}$} & \multirow[b]{2}{*}{ P-value } & \multicolumn{3}{|c|}{$\begin{array}{l}\text { Polyps from } \\
\text { tamoxifen non-users }\end{array}$} \\
\hline & No. & Mean & SD & & No. & Mean & SD & & No. & Mean & SD \\
\hline ER gland & 77 & 0.1 & 0.7 & $<0.0001^{\mathrm{c}}$ & 82 & 5.3 & 0.7 & 1.0000 & 247 & 5.9 & 3.2 \\
\hline ER stroma & 77 & 0.1 & 0.6 & $<0.0001^{c}$ & 83 & 4.8 & 0.6 & 1.0000 & 249 & 5.4 & 3.2 \\
\hline PR gland & 82 & 0.7 & 2.3 & $<0.0001^{\mathrm{c}}$ & 82 & 7.5 & 2.3 & $0.0014^{c}$ & 243 & 6.6 & 1.1 \\
\hline PR stroma & 83 & 0.6 & 2.0 & $<0.0001^{\mathrm{c}}$ & 83 & 6.3 & 2.0 & $0.0056^{\mathrm{c}}$ & 245 & 5.3 & 1.6 \\
\hline
\end{tabular}

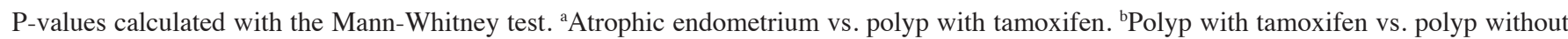
tamoxifen. ${ }^{\mathrm{P}} \mathrm{P}$-value corrected by the Bonferroni method (independent tests). BMI, body mass index; SD, standard deviation.

Table III. Comparison of the combination of final estrogen receptor (ER) and progesterone receptor (PR) scores in the glandular epithelium and stroma of benign polyps from tamoxifen users, benign polyps from tamoxifen non-users and atrophic endometrium $(n=420)$.

\begin{tabular}{|c|c|c|c|c|c|c|c|c|}
\hline \multirow[b]{2}{*}{ Final score } & \multicolumn{2}{|c|}{$\begin{array}{c}\text { Atrophic } \\
\text { endometrium }\end{array}$} & \multirow[b]{2}{*}{ P-value ${ }^{a}$} & \multicolumn{2}{|c|}{$\begin{array}{l}\text { Polyps from } \\
\text { tamoxifen users }\end{array}$} & \multirow[b]{2}{*}{ P-value ${ }^{b}$} & \multicolumn{2}{|c|}{$\begin{array}{l}\text { Polyps from } \\
\text { of tamoxifen non-users }\end{array}$} \\
\hline & No. & Percentage & & No. & Percentage & & No. & Percentage \\
\hline ER/PR epithelium & & & $<0.0001^{\mathrm{c}}$ & & & $1.0000^{\mathrm{d}}$ & & \\
\hline $\mathrm{ER}+/ \mathrm{PR}+$ & 0 & 0.0 & & 60 & 74.1 & & 197 & 82.4 \\
\hline ER+/PR- & 3 & 4.0 & & 1 & 1.2 & & 9 & 3.8 \\
\hline ER-/PR+ & 8 & 10.7 & & 20 & 24.7 & & 25 & 10.5 \\
\hline Receptor-positive & $11^{\mathrm{c}}$ & $14.7^{\mathrm{c}}$ & & $81^{c}$ & $100^{c}$ & & $231^{c}$ & $97.6^{c}$ \\
\hline ER-/PR- & $64^{c}$ & $85.3^{\mathrm{c}}$ & & $\mathbf{0}^{\mathrm{c}}$ & $\mathbf{0}^{\mathrm{c}}$ & & $8^{c}$ & $3.3^{\mathrm{c}}$ \\
\hline ER/PR stroma & & & $<0.0001^{\mathrm{c}}$ & & & $1.0000^{\mathrm{d}}$ & & \\
\hline $\mathrm{ER}+/ \mathrm{PR}+$ & 0 & 0 & & 58 & 70.7 & & 187 & 77.3 \\
\hline ER+/PR- & 2 & 2.6 & & 1 & 1.2 & & 16 & 6.6 \\
\hline ER-/PR+ & 7 & 9.2 & & 22 & 26.8 & & 28 & 11.6 \\
\hline Receptor-positive & 9 & 11.8 & & 81 & 98.8 & & 231 & 95.5 \\
\hline ER-/PR- & 67 & 88.2 & & 1 & 1.2 & & 11 & 4.5 \\
\hline
\end{tabular}

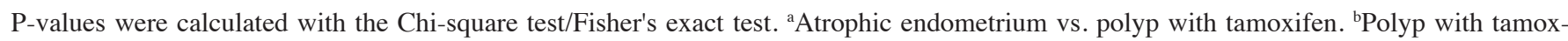

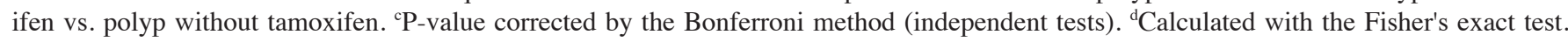
BMI, body mass index.

endometrium and the polyps from tamoxifen non-users, using the Mann-Whitney test corrected by the Bonferroni method (27,28). SAS software, version 9.2 was used and $\mathrm{P}<0.05$ was considered to indicate a statistically significant difference.

\section{Results}

Patient characteristics. The mean age of patients with benign polyps who used tamoxifen was 62.8 years $(\mathrm{SD} \pm 9.5)$, of patients with atrophic endometrium 63.1 years $(\mathrm{SD} \pm 8.6)$ and of patients with benign polyps who did not use tamoxifen 61.2 years $(\mathrm{SD} \pm 7.8)$. There was no statistically significant difference between the 3 groups $(\mathrm{P}=0.1737)$. The mean duration of tamoxifen use was 31.7 months (SD \pm 18.8) (data not shown). Postmenopausal bleeding and obesity were more common among women with polyps who were not treated with tamoxifen (Table I).

Hormone receptor expression. Comparing the mean final score for ER and PR, the polyps from tamoxifen users exhibited a higher ER/PR expression in the glandular epithelium and the stroma compared to the atrophic endometrium, with a statistically significant difference $(\mathrm{P}<0.0001)$. Compared to the polyps from women who had not been treated with tamoxifen, tamoxifen users exhibited a higher PR expression in the epithelium and stroma, with a statistically significant 
difference. Despite the lower ER expression in the glandular epithelium and stroma of the polyps from tamoxifen users, there was no statistically significant difference compared to the polyps from tamoxifen non-users (Table II).

On evaluating the combination of ER and PR expression in the atrophic endometrium, we observed that the majority of cases were ER-/PR- in the epithelium and the stroma. There were no ER+/PR+ cases. However, in the polyps from tamoxifen users as well as those from non-users, there was a high percentage of cases with hormone receptor positivity, the majority of which were ER+/PR+ (Table III).

\section{Discussion}

This study was conducted to evaluate the effect of tamoxifen on the expression of ER/PR in endometrial polyps from postmenopausal women. The results demonstrated that the polyps from tamoxifen users exhibited a higher ER/PR expression compared to the atrophic endometrium and a higher PR expression compared to the polyps from tamoxifen non-users.

To the best of our knowledge, this study on the immunohistochemical expression of hormone receptors in polyps from tamoxifen users is the largest case study in the literature to compare these three types of endometrial histology.

In the present study, we observed that the final score of ER/PR expression in the glandular epithelium and the stroma was significantly higher in polyps from tamoxifen users compared to the atrophic endometrium. We did not identify other studies in the literature that specifically evaluated polyps from tamoxifen users in relation to the atrophic endometrium to compare results. A previous study by Elkas et al (29) that evaluated benign endometrial samples from 20 tamoxifen users and 7 samples of atrophic endometrium from tamoxifen non-users, reported overexpression of ER and PR in the endometrial specimens of tamoxifen users compared to the controls. However, the patients included in the latter sample had received HT, which may have affected receptor expression (29).

A study by Schwartz et al (24) reported a higher PR expression in the glandular epithelium and a lower ER expression in the stroma of normal endometrium from women using tamoxifen when compared to atrophic controls. However, the authors of that study did not assess polyps (24).

A study by Dibi et al (15) that evaluated polyps and atrophic endometrium from tamoxifen users, reported a high progesterone expression in the polyps and the atrophic endometrium and a higher ER expression in the polyps.

Despite the wide diversity among those studies, they all reported that the endometrium exhibited a higher PR expression under tamoxifen treatment, which was in agreement with the results of our study.

As regards polyps from tamoxifen users, our study demonstrated a higher PR expression in the glandular epithelium and the stroma when compared to the polyps from non-users. Although there was a lower expression of ER in tamoxifen users, the difference was not statistically significant. The number of available similar studies in the literature is limited and the results are variable. Cohen et al (21) observed a lower ER expression in the epithelium and stroma of polyps from tamoxifen users, whereas McGurgan et al (22) reported this finding only in the epithelium and Schwartz et al (24) only in the stroma. As regards PR expression, McGurgan et al (22) demonstrated a higher expression in the stroma of polyps from tamoxifen users, whereas other studies did not report any difference $(21,24)$.

Our study did not identify a higher ER expression in the polyps from tamoxifen non-users compared to those from tamoxifen users, as described by certain studies $(17,21,24)$. This may be attributed to the fact that our tamoxifen non-user group had a higher body mass index (BMI). A previous study by Belisário et al (17) demonstrated that polyps removed from patients with a higher BMI exhibited a lower ER expression. Another factor that may have contributed to this result was the short period of tamoxifen use in our study, which had a mean duration of 31 months. In two previous studies conducted by Schwartz et al (24) and Cohen et al (21), the mean duration of tamoxifen use was 49 and 42 months, respectively.

Despite the heterogeneity of the studies and the results, assessing our results in conjunction with those reported in the literature, may lead to the conclusion that polyps exhibit a higher ER expression, regardless of tamoxifen use. These findings are consistent with those of other studies demonstrating a higher ER expression in the polyps from tamoxifen non-users compared to that in the adjacent atrophic endometrium $(15,23)$.

Tamoxifen appears to exert a limited effect on ER expression. Notably, this drug may act by increasing PR expression in endometrial polyps. This result is consistent with the histological findings in the polyps from tamoxifen users, which may present glandular secretory alterations and decidualization of the stroma, demonstrating a progestin effect $(30,31)$.

ERs are nuclear receptors that bind to a ligand and act as potent transcription factors, controlling the expression of several genes, including those that encode PR $(32,33)$. Thus, $\mathrm{PR}$ expression is not associated with the progestational status, but is a consequence of estrogen stimulation (34). Therefore, tamoxifen displays estrogen agonist activity, increasing the expression of PR in the endometrium.

The expression of ER seems to be linked to a process of self-regulation, dependent on hormonal factors, although this has not been fully elucidated (21). The increased expression of ER in polyps demonstrates a higher sensitivity of this type of tissue to estrogen.

A limitation of the present study is the immunohistochemical scoring method used. Automation has emerged as a reliable approach to evaluate immunohistochemical results. However, in the present study, we decided to evaluate the immunostaining visually, since this was considered to be the optimal way to avoid misinterpretations due to the high heterogeneity of the quality of the stored specimens. As this was a retrospective study, the specimens were of heterogeneous morphologic quality, which may have interfered with staining (may have resulted in background staining). Despite the gain in standardization, automation bases its analysis in thresholds set by the investigator and scores every case thereafter. Thus, a spot in which background is present, may be erroneously scored. In this example, subjectivity may be used in favor of reliability, as such a case may be eliminated from the analysis. In addition, previous studies have demonstrated the equivalence of the two methods $(35,36)$.

In conclusion, our results suggest that polyps frequently exhibit increased ER levels that are not necessarily dependent 
on the effect of tamoxifen. Furthermore, the high levels of PR appear to be consistent with the estrogenic effects of tamoxifen.

Although there appears to be a significant hormonal influence, the mechanism underlying the pathogenesis of a polyp has not been fully elucidated, neither has the precise effect of tamoxifen on the development of this endometrial alteration. It is hypothesized that additional mechanisms of action are involved.

\section{References}

1. Goldstein SR: Controversy about uterine effects and safety of SERMs: the saga continues. Menopause 9: 381-384, 2002.

2. Mourits MJ, De Vries EG, Willemse PH, Ten Hoor KA, Hollema $\mathrm{H}$ and Van der Zee AG: Tamoxifen treatment and gynecologic side effects: a review. Obstet Gynecol 97: 855-866, 2001

3. Katzenellenbogen JA, O'Malley BW and Katzenellenbogen BS: Tripartite steroid hormone receptor pharmacology: interaction with multiple effector sites as a basis for the cell- and promotor-specific action of these hormones. Mol Endocrinol 10: 119-131, 1996.

4. Osborne CK and Schiff R: Estrogen-receptor biology: continuing progress and therapeutic implications. J Clin Oncol 23: 1616-1622, 2005.

5. Shang Y and Brown M: Molecular determinants for the tissue specificity of SERMs. Science 295: 2465-2468, 2002.

6. Gielen SC, Kühne LC, Ewing PC, Blok LJ and Burger CW: Tamoxifen treatment for breast cancer enforces a distinct gene-expression profile on the human endometrium: an exploratory study. Endocr Relat Cancer 12: 1037-1049, 2005.

7. de Cremoux P: Hormone therapy and breast cancer. Bull Cancer 98: 1311-1319, 2011 (In French).

8. Gielen SC, Santegoets LA, Hanifi-Moghaddam P, Burger CW and Blok LJ: Signaling by estrogens and tamoxifen in the human endometrium. J Steroid Biochem Mol Biol 109: 219-223, 2008.

9. Curtis RE, Boice JD Jr, Shriner DA, Hankey BF and Fraumeni JF Jr: Second cancers after adjuvant therapy for breast cancer. J Natl Cancer Inst 88: 832-834, 1996.

10. Deligdisch L, Kalir T, Cohen CJ, de Latour M, Le Bouedec G and Penault-Llorca F: Endometrial histopathology in 700 patients treated with tamoxifen for breast cancer. Gynecol Oncol 78: 181-186, 2000.

11. Fisher B, Constantino JP, Redmond CK, Fisher ER, Wickerham DL and Cronin WM: Endometrial cancer in tamoxifen-treated breast cancer patients: findings from the National Surgical Adjuvant Breast and Bowel Project (NSABP) B-14. J Natl Cancer Inst 86: 527-537, 1994.

12. Maugeri G, Nardo LG, Campione $C$ and Nardo F: Endometrial lesions after tamoxifen therapy in breast cancer women. Breast J 7: 240-244, 2001.

13. Mignotte $\mathrm{H}$, Lasset $\mathrm{C}$, Bonadona $\mathrm{V}$, et al: Iatrogenic risk of endometrial carcinoma after treatment for breast cancer in a large French case-control study. Fédération Nationale des Centres de Lutte Contre le Cancer (FNCLCC). Int J Cancer 76: 325-330, 1998

14. Van Leeuwen FE, Benraadt J, Coebergh JW, et al: Risk of endometrial cancer after tamoxifen treatment of breast cancer. Lancet 343: 448-452, 1994.

15. Dibi RP, Zettler CG, Pessini SA, Ayub AV, de Almeida SB and da Silveira GP: Tamoxifen use and endometrial lesions: hysteroscopic, histological, and immunohistochemical findings in postmenopausal women with breast cancer. Menopause 16: 293-300, 2009.

16. Marttunen MB, Cacciatore B, Hietanen P, Pyrhönen S, Tiitinen A, Wahlström T and Ylikorkala O: Prospective study on gynaecological effects of two antioestrogens tamoxifen and toremifene in postmenopausal women. Br J Cancer 84: 897-902, 2001.

17. Belisário MS, Vassallo J, Andrade LA, Alvarenga M, Pinto GA and Monteiro IM: The expression of the hormone receptors in the endometrium and endometrial polyps in postmenopausal women and its relationship to body mass index. Maturitas 53: 114-118, 2006

18. Inceboz US, Nese N, Uyar Y, et al: Hormone receptor expressions and proliferation markers in postmenopausal endometrial polyps. Gynecol Obstet Invest 61: 24-28, 2006.
19. Sant'Anade AlmeidaEC,Nogueira AA, etal:Immunohistochemical expression of estrogen and progesterone receptors in endometrial polyps and adjacent endometrium in postmenopausal women. Maturitas 49: 229-233, 2004.

20. Lopes RG, Baracat EC, de Albuquerque Neto LC, Ramos JF, Yatabe S, Depesr DB and Lippi UG: Analysis of estrogen- and progesterone-receptor expression in endometrial polyps. J Minim Invasive Gynecol 14: 300-303, 2007.

21. Cohen I, Beyth Y, Altaras MM, et al: Estrogen and progesterone receptor expression in postmenopausal tamoxifen-exposed endometrial pathologies. Gynecol Oncol 67: 8-15, 1997.

22. McGurgan P, Taylor LJ, Duffy SR and O'Donovan PJ: Does tamoxifen therapy affect the hormone receptor expression and cell proliferation indices of endometrial polyps? An immunohistochemical comparison of endometrial polyps from postmenopausal women exposed and not exposed to tamoxifen. Maturitas 54: 252-259, 2006.

23. Mourits MJ, Ten Hoor KA, van der Zee AG, Willemse PH, de Vries EG and Hollema H: The effects of tamoxifen on proliferation and steroid receptor expression in postmenopausal endometrium. J Clin Pathol 55: 514-519, 2002.

24. Schwartz LB, Krey L, Demopoulos R, Goldstein SR, Nachtigall LE and Mittal K: Alterations in steroid hormone receptors in the tamoxifen-treated endometrium. Am J Obstet Gynecol 176: 129-137, 1997.

25. Fons G, Hasibuan SM, van der Velden $\mathrm{J}$ and ten Kate FJ: Validation of tissue microarray technology in endometrioid cancer of the endometrium. J Clin Pathol 60: 500-503, 2007.

26. Harvey JM, Clark GM, Osbome CK and Allred DC: Estrogen receptor status by immunohistochemistry is superior to the ligand-binding assay for predicting response to adjuvant endocrine therapy in breast cancer. J Clin Oncol 17: 1474-1481, 1999.

27. Holm S: A simple sequentially rejective multiple test procedure. Scand J Stat 6: 65-70, 1979.

28. Shaffer JP: Multiple hypothesis testing. Ann Rev Psychol 46: 561-584, 1995.

29. Elkas J, Armstrong A, Pohl J, Cuttitta F, Martínez A and Gray K: Modulation of endometrial steroid receptors and growth regulatory genes by tamoxifen. Obstet Gynecol 95: 697-703, 2000.

30. Corley D, Rowe J, Curtis MT, Hogan WM, Noumoff JS and Livolsi VA: Postmenopausal bleeding from unusual endometrial polyps in women on chronic tamoxifen therapy. Obstet Gynecol 79: 111-116, 1992.

31. Kennedy MM, Baigrie CF and Manek S: Tamoxifen and the endometrium: review of 102 cases and comparison with HRT-related and non-HRT-related endometrial pathology. Int J Gynecol Pathol 18: 130-137, 1999.

32. Green $S$ and Chambon P: Nuclear receptors enhance our understanding of transcription regulation. Trends Genet 4: 309-314, 1988.

33. Parker MG, Fawell SE, Lees JA, White R, Emmans CE and Danielian P: Function of estrogen receptor as a transcription factor: A target for antiestrogens. In: Origins of Human Cancer: A Comprehensive Review. Brugge J, Curran E, McCormick F (eds). Cold Spring Harbor Laboratory Press, Cold Spring Harbor, pp667-674, 1991 .

34. Brys M, Szyllo K, Romanowicz-Makowska H, Dobrowolski Z, Maslowska I and Krajewska W: Expression of estrogen and progesterone receptor genes in endometrium, myometrium and vagina of postmenopausal women treated with estriol. Sao Paulo Med J 127: 128-133, 2009.

35. Turashvili G, Leung S, Turbin D et al: Inter-observer reproducibility of HER2 immunohistochemical assessment and concordance with fluorescent in situ hybridization (FISH): pathologist assessment compared to quantitative image analysis. BMC Cancer 9: 165, 2009.

36. Turbin DA, Leung S, Cheang MC, et al: Automated quantitative analysis of estrogen receptor expression in breast carcinoma does not differ from expert pathologist scoring: a tissue microarray study of 3,484 cases. Breast Cancer Res Treat 110: 417-426, 2008. 